\title{
Computational Building Information Modelling for construction waste management: moving from rhetoric to reality
}

\begin{abstract}
There is a lively debate on the application of Building Information Modelling (BIM) to construction waste management (CWM). BIM can be utilised as a less expensive, virtual, graphical, and computational environment to enable designers to ponder different design options, or contractors to evaluate different construction schemes, both with a view to minimizing construction waste generation. However, although the debate too often treats BIM as a cure-all silver bullet, without some major hurdles being adequately addressed, the applications of BIM will remain rhetorical. This paper aims to demystify BIM by proposing its computational application to CWM. Based on a critical literature review, a prototypical framework of a computational BIM for CWM is delineated, within which the prerequisites of information readiness' and 'computational algorithms' are highlighted. Then, the paper details the required information and how it can be organised in a standalone database or encapsulated in existing BIM. Referring to the historical development of the similar database in the field of BIM-based cost management, this process could be tortuous but unavoidable. The paper also explores computational BIM algorithms that can manipulate the information to provide decision-making information for CWM, such as low-waste design or construction options. Although the framework has been substantially developed as a result of this study, it is not to be taken as an immediately applicable solution but rather as a shared footing based on which future development of computational BIM for CWM will proceed in a more efficient and effective fashion.
\end{abstract}

Keywords: Building Information Modelling (BIM); Construction waste management (CWM); Computational design

\section{Introduction}

While construction is a noble industry essential for materialising the built environment, which influences human health, economic activities and social behaviour, it also exerts grievous, adverse impacts on the natural environment in the form of resource depletion, greenhouse gas (GHG) emissions, noise, dust, and disposal of construction waste. Construction waste, sometimes called construction and demolition (C\&D) waste, is defined as the surplus and damaged products and materials that arise from construction, renovation, and demolition activities (Roche and Hegarty, 2006). It often constitutes a prodigious portion of total municipal solid waste that contributes to degradation of the environment. For example, in the U.S., the estimated amount of building-related waste generated in 2003 was 170 million tons (USEPA, 2013). At present, the construction industry is responsible for about $32 \%$ of landfill waste and $25 \%$ of all used raw materials in the UK (Prism Environment, 2012). The European Commission (2013) reported that construction waste is responsible for $25-30 \%$ of all waste generated in the European Union. In Hong Kong, the solid waste ending up in landfills reached 14,311 ton per 
day (tpd) in 2013, of which 25\% was from construction activities (HKEPD, 2015), whereas, in

During the process of devising such approaches to construction waste management (CWM), Building Information Modelling (BIM) has been increasingly explored. According to the U.S. National BIM Standard (2007), BIM is "a digital representation of physical and functional characteristics of a facility and a shared knowledge resource for information about a facility forming a reliable basis for decisions during its life cycle" (p.149). Davies and Harty (2011) expounded that BIM is a term used to refer to a family of technologies and related practices used to represent and manage the information used for, and created by, the process of designing, constructing and operating buildings. With its 3D presentation and virtual reality simulation capability, BIM was introduced as a technical tool that can be applied to improve the construction industry in a number of areas, such as design quality enhancement, construction plan rehearsal and optimisation, and site management (CIFE, 2007; Kaner et al., 2008; Li et al., 2009). On the other hand, BIM has an indirect, yet probably more significant impact on projects by overcoming the many inherent problems in project organisations. For instance, with its information interoperability and 3D presentation, BIM can improve communication amongst parties (Fischer and Kunz, 2004). As a continuing digital platform, it can retain the information or knowledge (e.g. design rationale) to reduce discontinuity (Li et al., 2009). BIM can also be used to encourage integration and collaboration (Taylor and Bernstein, 2009), particularly when used in collaboration with the integrated project delivery model (AIA and AIA CC, 2007; Sive, 2009). Partly owing to these potential benefits, BIM has been enthusiastically advocated as a solution to CWM.

The UK's Construction 2025 Strategy states that "BIM has the potential to reduce construction waste during design and construction stages" (HM Government, 2013), and many professionals in the industry, such as architects, engineers and surveyors, take this a step further by considering BIM to be a silver bullet in the battle against construction waste. The rhetoric includes widely propagated potential benefits of BIM, such as clash detection and on-site coordination, with the assumption that they will automatically become a reality. This is indicative of the mystery surrounding BIM's application to CWM. Without demystifying the mystery, BIM will remain a fad. There are a number of academic studies using a normative approach to examine how BIM and CWM can be joined or juxtaposed (e.g. Baldwin et al., 2009; Porwal and Hewage, 2012; Cheng and Ma, 2013; Porwal, 2013; Liu et al., 2015). While these 
studies are critiqued later in the paper, generally speaking they add to the rhetoric rather than clarify the issue.

Drawing upon the experiences in both BIM and CWM research, this paper helps to move BIM-enabled CWM from rhetoric towards reality. It does so by stressing the importance of information in a BIM initiative and the need to develop a database that stores state-of-the-art waste generation levels of various design options and construction schemes. The argument is that with such a database of information in place, BIM can then be utilised as a virtual computational environment within which designers and contractors can manipulate different design and construction options with a view to minimizing construction waste.

In order to deal with the topic in a clear and logical manner, the paper is divided into four main sections subsequent to this first introductory section. Section 2 is a critical assessment of the existing studies on the application of BIM to CWM, while section 3 delineates the prototypical framework of computational BIM for CWM and highlights the framework's two essential prerequisites of information readiness and computational algorithms to manipulate the information for decision-making. Section 4 details the required information by suggesting the development of two databases, namely, the 'Design Options - Waste Generation' database and the 'Construction Schemes - Waste Generation' database. Section 5 explores how BIM can be developed into a computational environment that will allow different design options and construction schemes to have their waste generation levels calculated instantaneously. Although the framework has been elaborated to a large extent, it has not been fully developed as a solution that can help implement BIM for CWM immediately. The intention is rather that the framework should provide a promising direction in which future studies on BIM for CWM can proceed more effectively and efficiently.

\section{Literature review}

There is a limited but growing body of literature exploring how BIM can be implemented for CWM. Porwal and Hewage (2012) conducted a BIM-enabled analysis to minimize the waste rate of structural reinforcement. They did so by selecting BIM as the hub for communicating project information among various design teams (e.g. architectural, structural, mechanical) and then using an optimization algorithm to minimize reinforcement waste. Cheng and Ma (2013) developed a BIM-based system for demolition and renovation waste estimation, and waste disposal planning. While their research illustrated the importance of information to make BIM truly useful for CWM, it did not articulate the key information required to develop a convincing algorithm to perform the estimation based on the information. Research from Loughborough University advocated 'designing out' construction waste (Osmani et al. 2008; Baldwin et al., 2009). Their works were espoused by a Generic Process Model for the detailed design process and a technique known as the Design Structure matrix (DSM), which is developed in-house and promoted as a major decision-support system by the school. In their recent work, BIM was proposed as a potential design decision-making tool to support effective CWM (Liu et al., 2015). 
Whilst the above studies have not convincingly linked BIM and CWM, they have at least identified the sources of construction waste generation as a starting point. In CWM literature, many researchers have focused on on-site waste management by viewing it as the stage where waste is actually generated. On-site operations such as construction methods, materials handling skills/practices (Shen et al., 2004), housing keeping (Trigunarsyah et al., 2006), on-site sorting (Yuan et al., 2013), and off-site sorting (Lu and Yuan, 2012), have all had a significant impact on waste generation, although a certain level of waste generation is perceived as unavoidable (Teo and Loosemore, 2001). As construction adopts a contracting/sub-contracting system, researchers have extended CWM to the downstream construction supply chain by managing sub-contractors, advocating green procurement (Ofori, 2000), or extending producer responsibilities (Acree and Horvath, 2003). Those advocating 'design out' construction waste ascertain that designers have a decisive role in helping waste reduction, although survey results have shown that this has only been sporadically practised (e.g. Yuan, 2013; Wang et al., 2014a). Minimization of construction waste is still secondary to the traditional project objectives of time, cost, and quality. The UK-based WRAP (Waste \& Resources Action Programme) (2007), conducted a comprehensive study to identify five key principles that design teams can use to reduce construction waste, which were cited by Liu et al. (2015) as: (a) Design for reuse and recovery; (b) Design for off-site construction; (c) Design for materials optimisation; (d) Design for waste efficient procurement; and (e) Design for deconstruction and flexibility. The measures outlined in WRAP's (2007) report are guided by the '3Rs' principle of 'reduce, reuse, and recycle' and by classifying waste management strategies according to their desirability (Peng et al., 1997). As a result of the foregoing research, it has become clear that decisions made at both the design and construction stages have an impact on construction waste generation.

So what can BIM offer to minimize construction waste generation? In simple terms, BIM is a digital representation of physical and functional characteristics of a facility that aims to facilitate the exchange and interoperability of information (Eastman et al., 2008). BIM is a "richer repository" (Eastman, 1999) than a set of drawings or static CAD files, since it has the ability to store different types of information and contains both geometric and non-geometric information about the project (Pratt, 2004). Geometric information includes size, volume, shape and spatial relationships, while non-geometric information includes the type of individual construction component, specifications of material, construction schedule, and cost. Schlueter and Thesseling (2009) claimed that BIM information should include geometric, semantic and topological information. Geometric information directly relates to the building form in three dimensions; semantic information describes the properties of components, i.e., more advanced rule and function information; and topological information captures the dependencies of components. Without all the available information, BIM cannot do anything meaningful. The level of development (LOD) and specification defined by BIMForum (2013) not only stresses the importance of information in BIM but also goes further to specify which development level of the information, ranging from 100 to 400 , corresponds to BIM functionalities, e.g. for quick 
demonstration, or for fabrication, assembly, and installation. The momentum that BIM has gained can be better understood by Flanagan and Lu's (2008) philosophical contention that managing a construction project involves using available information and knowledge to make an array of decisions across processes including architecture, engineering, construction, and operation. The main objective of information management is to support decision-making by ensuring that accurate information is always available at the right time in the right format to the right person to allow making informed decisions (Chen et al., 2015). If properly devised, BIM is a useful platform that can provide this decision-support information.

Assuming that all the information needed is ready, what makes BIM a useful decision-making tool for construction waste management? BIM can provide a less expensive, virtual, graphical, and computational environment to ponder various design options and construction schemes, which have a decisive impact on construction waste minimization; this is computational design thinking. Owing to construction projects' heavy physical resource engagement, and their one-off, irreversible nature, it is too expensive if not entirely impossible to try different design and construction schemes before a project is actually built. This leads to two major problems. First, design errors arising from the design stage cannot be effectively identified in advance (Li et al., 2009), which could cause substantial disruption or loss, including construction waste, when the errors are discovered. Second, different construction schemes cannot be tried and rehearsed in advance ( $\mathrm{Li}$ et al., 2009) and are developed at the planning stage where there is a heavy reliance on rules of thumb and experience. A not-well-thought-out construction scheme may cause problems in the delivery of a project, including not be able to achieve minimal construction waste generation. However, BIM can provide the virtual environment to undertake these works. With all the detailed 3D models of building available in the BIM component library (Huang et al., 2007), it is possible to create a 3D presentation of a construction project rapidly and affordably. The virtual environment allows designers to ponder different options conveniently with the changes of presentations, functionalities, quantities, or in this case, waste generation being computed instantaneously and presented graphically in the form of a dashboard.

Nevertheless, as the digital representation of a physical facility, BIM itself cannot manipulate information to allow informed decision-making for CWM; it relies on algorithms tailor-made for this purpose. This was captured in Porwal's (2013) work by articulating that construction waste generation can be determined by both design and construction stages, and by developing a system dynamics (SD) model to estimate waste generation in relation to different design and construction combinations. Although the authors of this paper agree with exploring computational BIM for CWM, they think that the SD model should be curtailed owing to its black-box nature and the mixing of responsibilities between design and construction, and that algorithms are the way to go.

To summarize, there is a growing body of literature exploring how BIM can be used to minimize construction waste. However, there are several mysteries surrounding BIM that need to be 
demystified before it can be really implemented for CWM. BIM can provide a less expensive,

\section{The prototypical framework}

Fig. 1 illustrates the prototypical framework of computational BIM for CWM. It covers the design and construction stages, which play a decisive role in determining the generation of construction waste. It emphasizes that human beings (e.g. the designers and contractors in Fig. 1) are the decision-makers at the core, while BIM is a technology to facilitate the decision-making processes. Based on BIM, a designer ponders different design options, which are formed by various 3D parametric models stored in the BIM component library; a procedure similar to playing with Lego. In this case, the 3D models are linked to a particular database indicating state-of-the-art average waste generation levels if the models are adopted. For example, one can evaluate whether a bay window or a balcony should be designed by meeting various design criteria, such as cost, functions, energy consumption, and waste minimization.

\section{$<<$ Please insert Fig. 1 here $>>$}

Likewise, in the BIM environment, a construction planner ponders different construction schemes, each of which is linked to the database indicating the most updated, average waste generation levels if that scheme is adopted. For example, the planner can evaluate whether timber or metal formwork should be selected, given the required criteria such as buildability, cost, time, quality standard, and waste minimization. In real design and construction practice, construction waste minimization will rarely be singled out but considered in conjunction with the criteria such as time, cost, quality, safety, sustainability, and so on. All these design and construction evaluations are undertaken in a virtual environment without engaging heavy and physical resources. All related design and construction documentations, including quantity take-offs, counts, and measurements, are automatically updated if any changes are made to the BIM design (Porwal, 2013). It is thus less costly to coordinate design and construction changes.

Currently, neither commercial BIM solutions nor academic studies have sufficiently extended BIM to perform CWM, despite widespread calls to do so. As previously argued, the application of BIM to CWM rely on two essential prerequisites, namely, information readiness and computational algorithms to manipulate the information for decision-making. The two components are highlighted in the conceptual framework and are elaborated upon in following sections.

\section{The design options/construction schemes - waste generation database}

Although there should be two separate databases indicating the average waste generation levels 
caused by different design options or construction schemes, because of their similarities they are

The databases can be standalone. This form will help focus on the commitment to develop the databases. The burdensome task of exhaustively listing the myriad of building components and organizing them in a hierarchical structure can be conducted with the maturity of BIM ontology, which has defined structure and acts as a shared vocabulary that formally describes all BIM terms in an unambiguous manner (Lee and Jeong, 2012). For example, the component ontology provides the description of components and their decomposition, while the relationship ontology defines the geometrical relationship between two or more components. Furthermore, as BIM ontology can be interpreted in a consistent way and is expansible, it facilitates acquiring and sharing information in BIM (Succar, 2009) and can respond to the increasing requirements of BIM users. The databases can also be linked to the BIM component library or the building information model itself by using record linkage (Dunn, 1946), a term used by statisticians, epidemiologists, and historians, among others, to describe the process of joining records from one data source to another that describe the same entity. Fig. 3 illustrates how these databases are linked together.

\section{$<<$ Please insert Fig. 3 here $>>$}

The databases can also be merged into the existing BIM component library. Fig. 4 is a sample of the existing BIM component library from Autodesk Revit. The main area is the 3D graphical presentation of the facility, formed by various components. The grids on the left-hand side is the dashboard for both geometric and non-geometric information of the BIM components, as can be seen in any model created by Autodesk Revit. What is different is the additional columns called 'design waste generation level', 'construction waste generation level', 'design waste amount', and 'construction waste amount', all of which can be perceived as new properties that can be encapsulated in the components. Similar to material specifications, construction schedule, and costs, the columns become the non-geometric information of the component, which could be further expanded by adding other properties such as energy. Actually, a building information model, regardless of its 3D presentation and information richness, can be perceived as a relational database per se from the perspective of computer database experts (Wang et al., 2013; Liu et al., 2015b). Some information is initially contained in the model, while others are 
continuously generated and imported to the model throughout the project life cycle. Through a certain mapping approach, information from an external source, such as a MS Excel file or MS Access, can be linked to the entire project or a specific component (Xie et al., 2011; Wang et al., 2014b; Kang and Hong, 2015).

$<<$ Please insert Fig. 4 here $>>$

\section{The computational BIM}

With the information in place, computational BIM algorithms are required to manipulate the information in the BIM and provide decision-making information for CWM, such as low waste design options and construction schemes. The flowchart for developing the computational BIM for measuring waste generation at the design or construction stage is illustrated in Fig. 5. Prior to a detailed description, it should be noted that there are two typical modes for BIM of a construction project. One is that the model is developed by the designer at the design stage and is then shared with the contractor for construction planning, while the other is that the contractor develops the model on his own. As the computation of waste generation under these two modes follows a similar logic, for simplification this study only considers the situation where the designer and contractor develop their own separate building information model.

$$
<<\text { Please insert Fig. } 5 \text { here }>>
$$

\subsection{Measuring waste generation at the design stage}

The first step is to develop the building information model. Unlike traditional methods that use lines, points, and arcs to draw the building components, a designer directly uses 3D digital objects to create the model in commercial BIM software (e.g. Autodesk Revit and ArchiCAD). Each of the objects, regardless of being provided by BIM software, developed by the designer himself/herself, or exported from a third-part library, has various parameters such as length, area, thickness, volume, offset, level, and slope. The parameters have initial values, which can be modified and changed. For example, the designer selects a window with an initial size of $1000 \mathrm{~mm} * 500 \mathrm{~mm}$ from the component library, but can then easily adjust both width and height if the window does not fit the design requirements.

Before moving forward to the second step, one important issue is to check and revise the name and type of the object, which lays the foundation for mapping the component with its waste generation level. Application program interface (API) is used to build the connection between BIM and Design Options - Waste Generation (DO-WG) databases. Depending on the BIM software used, the connection can be programmed in different languages. After the connection is developed, the waste generation level of each component in the BIM model is automatically acquired by matching the component in the model with the database (See Fig. 6).

$$
\text { <<Please insert Fig. } 6 \text { here >> }
$$


The third step is to calculate the amount of waste and present the results. BIM can automatically measure the quantity of each component. Depending on the type of the building object, the quantity can be presented by area, volume, or piece. Together with the waste generation level, the waste generation of one object can be denoted as Equation [1]:

$$
W_{D i}=Q_{D i} \times L_{D i}
$$

Where $W_{D i}$ is the waste generation of the component $i$ under the current design option, $Q_{D i}$ is the quantity of the component $i$, and $L_{D i}$ is the waste generation level stored in the DO-WG database.

The total waste $W_{D}$ can then be denoted as Equation [2]:

$$
W_{D}=\sum_{1}^{n} W_{D i}
$$

Finally, the designer can review the waste generation in BIM software, and find which component in a certain design option causes a large amount of waste (shown in Fig. 7). Based on the waste generation and other criteria, the designer will decide whether the original design should be improved. If the design is modified, the above steps will be repeated to calculate the latest waste generation. The whole process can be swiftly reiterated in the BIM environment without involving a large amount of resources.

\section{$<<$ Please insert Fig. 7 here $>$}

\subsection{Measuring waste generation at the construction stage}

Similarly to evaluating waste generation at the design stage, the waste generation at the construction stage is measured following the four steps: (1) Developing the BIM model for construction works; (2) Linking the model and the Construction Schemes - Waste Generation (CS-WG) database; (3) Calculating the amount of waste; and (4) Reviewing the results. In reality, contractors often need to reconsider or even optimize the design from a buildability perspective. In this case, waste generation, amongst other criteria such as time, cost, and quality, is taken into consideration. Mathematically, the waste generation of a certain construction scheme can be shown as Equation [3]:

$$
W_{C i}=Q_{C i} \times L_{C i}
$$

Where $W_{C i}$ is the waste generation of the construction scheme of component $i, Q_{C i}$ is the quantity of the component $i$ using the construction scheme and $L_{C i}$ is the waste generation level stored in the CS-WG database.

The total waste $W_{C}$ can then be denoted as Equation [4]:

$$
W_{C}=\sum_{1}^{n} W_{C i}
$$

In addition, if the construction schedule is integrated with the model, the waste generation along with the construction process will be illustrated in a BIM environment. Such direct illustration has two benefits: firstly, the constructor can have a clear understanding of the amount of waste 
generated in each construction work, which will be one of the criteria for analyzing whether the current scheme is appropriate; secondly, site managers can use it as a baseline to timely arrange transportation for construction waste delivery, thereby helping to maintain a clean and organized site.

\section{Discussion}

The above sections introduced computational BIM for CWM, and detailed the two essential components, i.e., the BIM information readiness and the computational algorithms to manipulate the information. However, it is unlikely that computational BIM for CWM will become a reality any time soon. There is still a long way to go in its development, which can be better understood by comparing it to the historical development of BIM-based cost estimating. In the early days, BIM was mainstreamed to bring about a revolutionary impact on cost estimating in quantity surveying practices prevailing in Commonwealth countries. As a BIM model contains 3D objects with geometrical information, it is easy to capture the quantities of objects whose volumes and areas can be automatically and instantly extracted (Jiang, 2011; Kymmell, 2008) to form the basis of an accurate cost estimate after mapping them against the cost database. This is comparable to comptunational BIM for CWM, wherein the quantities are similar to the quantities of all the components (see Equations [1] and [3]) and the cost database is similar to the DO-WG or the CS-WG database. Wu et al. (2014) reviewed the BIM-based cost estimating in UK quantity surveying practice, and identified several key challenges in terms of information exchange, model quality, and UK standards. These key challenges can also be identified in the development of computational BIM for CWM.

In comparsion with the DO-WG or the CS-WG database, the cost index database is more mature. In its simplest form, the cost index database, includes material types, labour, professional services, and their corresponding prices, which should reflect the locality and keep updated with market fluctuation. The complexity to develop the cost database is considerably high, but owing to efforts over the past decades from surveying firms such as Langdon \& Seah and Rider Levett Bucknall enduringly collecting and publishing cost indexes in various economies, the cost index database nowadays is acceptable as a common baseline by clients, contractors, and consultants for estimating building costs. Researchers specialising in CWM have endveavored to investigate waste generation rates (WGRs), which can form an important part of the DO-WG or the CS-WG databases (See Fig. 2). A WGR can be calculated by dividing the waste in volume $\left(\mathrm{m}^{3}\right)$ or quantity (tons) by either the amount of virgin materials purchased, or the amount required by the design, or per $\mathrm{m}^{2}$ of gross floor area (Formoso et al., 2002). Researchers have used diverse methods to collect the data for calculating WGRs: direct observation (Poon et al., 2001); questionnaire survey (McGregor et al., 1993); sorting and weighing the waste materials on-site (Bossink and Brouwers, 1996); collecting data through consultation with construction company employees (Treloar et al., 2003); and tape measurement and truck load records (Skoyles, 1976; Poon et al., 2004). A problem is that most of the studies had a relatively small sample or sampled relatively small sites due to the difficulties involved in conducting a full coverage survey over a 
long period of time (Katz and Baum, 2011; Lu et al., 2011) and the reported WGRs are too divergent to be accepted with confidence. Recently, researchers have utilised big data in the hope of deriving more convergent WGRs (e.g. Lu et al., 2015a; 2015b). In view of the development of BIM-based cost estimating and the advancement of CWM, it is not overly optimistic to expect that the DO-WG and the CS-WG databases will one day be fully developed, despite the laboriuosly slow process of collecting the necessary data.

The computational algorithms as shown in Equations [1] to [4] will not be free from criticisms for their linearity. It might be considered overly simplified to decompose a design into different options or a construction scheme into different trades to examine their unit construction waste generation. Construction waste generation is perhaps better understood by putting it in a system rather than by examining the individual components that form the system. In a sense, Porwal's (2013) system dynamics model backed by high order equations is better suited to capture waste generation in the design and construction stages as a whole. However, the model mixes the responsibilities of designers and contractors in CWM, which blurs the direct effects of changing design options or construction schemes on waste minimization. The intuitive suggestion is to examine the linear relationships between design options/construction schemes and their waste generation and make them more robust for developing computational BIM for CWM. Although the discussion has not provided an immediate solution to computational BIM for CWM, it has nevertheless demystified several typical confusions surrounding the issue.

\section{Conclusion}

Exploration of BIM has too often assumed it to be a silver bullet that can fix anything, including CWM. While it is true that BIM can provide a less expensive, virtual, graphical, and computational environment to enable decision-makers to evaluate different design options or construction schemes so as to manage construction waste more effectively, many issues remain to be demystified before BIM can be effectively used for CWM. This paper proposes a computational BIM for CWM by firstly delineating a prototypical framework and then elaborating its two prerequisites, including information readiness and computational algorithms. Using a normative approach, the authors argue that the key information should be the average waste generation levels, i.e. waste generation rates (WGRs) associated with different design options or construction schemes. The key information can be organized in standalone databases but connected with a BIM, or be encapsulated in the existing BIM components to become their new properties; research into WGRs will help develop the key information. Referring to the historical development of the building cost index, the process will not be easy but it is a promising direction that cannot be avoided.

The computational algorithms developed in this study can automatically calculate the quantities of a design option/construction scheme for BIM, instantaneously mapping them to the WGRs database and estimating the potential amount of waste generated. Using some graphical presentation skills, such as pie chart and spider diagrams, results can be displayed graphically in 
the form of a dashboard to support designers and contractors when making decisions in relation to CWM. The linearity of the algorithms may not entirely reflect the nature of construction waste generated by the decisions made at the design or construction stage, but the idea is to have straightforward algorithms so that designers and contractors will have a clear understanding of the impact of their decisions on construction waste generation, and their responsibilities will not be mixed up or shifted to each other.

The paper is deliberately presented in an exploratory and discursive way, and the computational BIM for CWM is proposed in a normative rather than a positive fashion. Based on the authors' many years of research experiences in both fields, the aim is not to provide an immediate solution to computational BIM for CWM but rather to demystify the typical confusions surrounding this issue. Future studies are recommended to further develop the design/construction - waste generation level by embracing advancements in information technology and CWM. It is hoped that through the study presented in this paper, development of computational BIM for CWM will proceed more efficiently and effectively.

\section{Acknowledgements}

This study is jointly supported by the General Research Fund (Project Code: 17205614) of the Hong Kong Research Grant Council (RGC), the Innovation and Technology Fund (Project Code: ITP/045/13LP) of the Hong Kong Innovation and Technology Commission (ITC), and the National Natural Science Foundation of China (NSFC) (Project Code: 71273219).

\section{References}

Acree G.A. and Horvath, A. (2003). Strategies of extended producer responsibility for buildings. Journal of infrastructure systems, 9(2), 65-74.

AIA and AIA CC (2007). Integrated Project Delivery: A Guide. AIA's Documents Committee and AIA California Council.

Baldwin, A., Poon, C.S., Shen, L.Y., Austin, S. and Wong, I. (2009). Designing out waste in high-rise residential buildings: Analysis of precasting methods and traditional construction. Renewable Energy, 34, 2067-2073.

BIMForum (2013). Level of development specification - for building information models. retrieved

from http://bimforum.org/wp-content/uploads/2013/08/2013-LOD-Specification.pdf (accessed 22 September 2015).

Bossink, B. A. G. and Brouwers, H. J. H. (1996). Construction waste: Quantification and source evaluation. Journal of Construction Engineering and Management, 122(1), 55-60.

Center for Integrated Facility Engineering (CIFE) (2007). CIFE Technical Reports. http://cife.stanford.edu/Publications/index.html. (accessed on 8th Aug 2015).

Chen, K., Lu, W.S., Peng, Y., Rowlinson, S.M., and Huang, G.Q (2015). Bridging BIM and building: From a literature review to an integrated conceptual framework. International Journal of Project Management. 33(6), 1405-1416. 
Cheng, J. C. and Ma, L. Y. (2013). A BIM-based system for demolition and renovation waste estimation and planning. Waste management, 33(6), 1539-1551.

Davies, R. and Harty, C. (2011). Building Information Modelling as innovation journey: BIM experiences on a major UK healthcare infrastructure project. In 6th Nordic Conference on Construction Economics and Organisation-Shaping the Construction/Society Nexus.

Dunn, H.L. (1946). Record Linkage. American Journal of Public Health, 36, 1412-1416.

Eastman, C. M., Teicholz, P., Sacks, R., and Liston, K. (2008). BIM Handbook: a guide to building information modeling for owners, managers, architects, engineers, contractors, and fabricators. Hoboken.

Eastman, C.M. (1999). Building Product Models: Computer Environments Supporting Design and Construction. CRC, Boca Raton.

EC (European Commission) (2015). Construction and Demolition Waste (CDW). http://ec.europa.eu/environment/waste/construction_demolition.htm, accessed on 12 September 2015.

Fischer, M. and Kunz, J., (2004). The Scope and Role of Information Technology in Construction. http://cife.stanford.edu/online.publications/TR156.pdf.

Flanagan, R. and Lu, W.S. (2008). Making informed decisions in product-service systems. IMechE Conference, Knowledge and Information Management Through-Life. Institute of Mechanical Engineers.

Formoso, C. T., Soibelman, L., De Cesare, C., and Isatto, E. L. (2002). Material waste in building industry: main causes and prevention. Journal of construction engineering and management, 128(4), 316-325.

HKEPD (2015). Hong Kong Waste Treatment and Disposal Statistic. shttp://www.epd.gov.hk/epd/english/environmentinhk/waste/data/stat_treat.html, accessed on $21 / 09 / 2015$.

HM Government (2013). Building Information Modelling Industrial strategy: government and industry in partnership. London, UK. Available at: https://www.gov.uk/government/uploads/system/uploads/

Huang, T., Kong, C.W., Guo, H.L., Baldwin, A. and Li, H. (2007). A virtual prototyping system for simulating construction processes. Automation in Construction, 16, 576-85.

Jiang, X. (2011). Developments in Cost Estimating and Scheduling in BIM Technology. Northeastern University.

Kaner, I., Sacks, R., Kassian, W., and Quitt, T. (2008). The pace of technological innovation in architecture, engineering, and construction education: Integrating recent trends into the curricula. Journal of Information Technology in Construction, 13, 303-323.

Kang, T. W. and Hong, C. H. (2015). A study on software architecture for effective BIM/GIS-based facility management data integration. Automation in Construction, 54, 25-38.

Katz, A. and Baum, H. (2011). A novel methodology to estimate the evolution of construction waste in construction sites. Waste management, 31(2), 353-358. 
Kymmell, W. (2008). Building Information Modeling: Planning and Managing Construction Projects with $4 D C A D$ and Simulations. New York: McGraw Hill Companies.

Lee, J. and Jeong, Y. (2012). User-centric knowledge representations based on ontology for AEC design collaboration. Computer-aided Design, 44(8), 735-748.

Li, H., Lu, W.S., and Huang, T. (2009). Rethinking project management and exploring virtual design and construction as a potential solution. Construction Management and Economics, 27 (4), 363-371.

Liu, H., Al-Hussein, M., and Lu, M. (2015b). BIM-based integrated approach for detailed construction scheduling under resource constraints. Automation in Construction, 53, 29-43.

Liu, Z., Osmani, M. Demian, P., and Baldwin, A. (2015a). A BIM-aided construction waste minimisation framework. Automation in Construction, 59, 1-23.

Lu, W.S. and Yuan, H. (2012). Off-site sorting of construction waste: What can we learn from Hong Kong? Resources, Conservation and Recycling, 69, 100-108.

Lu, W.S., Chen, X., Ho, D. C., and Wang, H. (2015a). Analysis of the construction waste management performance in Hong Kong: the public and private sectors compared using big data. Journal of Cleaner Production. doi:10.1016/j.jclepro.2015.06.106.

Lu, W.S., Chen, X., Peng, Y., and Shen, L. (2015b). Benchmarking construction waste management performance using big data, Resources, Conservation and Recycling, forthcoming.

Lu, W.S., Yuan, H., Li, J., Hao, J.L., Mi, X., and Ding, Z. (2011). An empirical investigation of construction and demolition waste generation rates in Shenzhen city, South China. Waste management, 31(4), 680-687.

McGregor, M, Washburn, H., and Palermini, D. (1993). Characterization of Construction Site Waste: Final Report. Presented to the METRO solid waste department, Portland, Oregon.

MoE (2014). History and Current State of Waste Management in Japan. http://www.env.go.jp/en/recycle/smcs/attach/hcswm.pdf, accessed on 21/09/2015.

NBIMS (2007). National Building Information Modeling Standard Part-1: Overview. Principles and Methodologies. US National Institute of Building Sciences Facilities Information Council. BIM Committee.

Ofori, G. (2000). Greening the construction supply chain in Singapore. European Journal of Purchasing and Supply Management, 6(3), 195-206.

Osmani, M., Glass, J., and Price, A.D.F. (2008). Architects' perspectives on construction waste reduction by design. Waste Management, 28(7), 1147-1158.

Peng, C. L., Scorpio, D. E., and Kibert, C. J. (1997). Strategies for successful construction and demolition waste recycling operations. Construction Management and Economics, 15(1), 49-58.

Poon, C. S., Ann, T. W., and Ng, L. H. (2001). On-site sorting of construction and demolition waste in Hong Kong. Resources, conservation and recycling, 32(2), 157-172.

Poon, C. S., Yu, A. T. W., Wong, S. W., and Cheung, E. (2004). Management of construction waste in public housing projects in Hong Kong. Construction Management and Economics, 22(7), 675-689. 
Porwal, A. (2013). Construction Waste Management at Source: a Building Information

Porwal, A. and Hewage, K. (2012). Building Information Modeling-Based Analysis to Minimize Waste Rate of Structural Reinforcement. Journal of Construction Engineering and Management, 138(8), 943-954.

Pratt, M.J. (2004). Extension of ISO 10303, the STEP standard, for the exchange of procedural shape models. Proceedings of Shape Modeling Applications. IEEE, pp. 317-326.

Prism environment (2012). Construction sector overview in the UK. Available at: http:// www.prismenvironment.eu/reports_prism/UK_PRISM_Environment_Report_EN.pdf (accessed 24 September 2015).

Roche, T.D. and Hegarty, S. (2006). Best practice guidelines on the preparation of waste management plans for construction and demolition projects. http://goo.gl/LKxNsa. Accessed on 21/09/2015.

Schlueter, A. and Thesseling, F. (2009). Building information model based energy/exergy performance assessment in early design stages. Automation in Construction, 18, 153-163.

Shen, L. Y., Tam, V. W., Tam, C. M., and Drew, D. (2004). Mapping approach for examining waste management on construction sites. Journal of Construction Engineering and Management, 130(4), 472-481.

Sive, T. (2009). Integrated Project Delivery: Reality and Promise, A Strategist's Guide to Understanding and Marketing IPD, Society for Marketing Professional Services Foundation, July 2009.

Skoyles, E.R., 1976. Materials wastage - a misuse of resources. Building Research and Practice (July/August 1976), 232-243.

Succar, B. (2009). Building information modelling framework: A research and delivery foundation for industry stakeholders. Automation in Construction, 18(3), 357-375.

Taylor, J. E. and Bernstein, P. G. (2009). Paradigm trajectories of building information modeling practice in project networks. Journal of Management in Engineering, 25(2), 69-76

Teo, M. M. M. and Loosemore, M. (2001). A theory of waste behaviour in the construction industry. Construction Management and Economics, 19(7), 741-751.

Treloar, G.J., Gupta, H., Love, P.E.D., Nguyen, B. (2003). An analysis of factors influencing waste minimization and use of recycled materials for the construction of residential buildings. Management of Environmental Quality: An International Journal, 14(1), 134-145.

Trigunarsyah, B., Sofyan, I. G., and Hendi, H. (2006). Housekeeping management as a strategy to minimize construction waste in high rise building projects. In Kanok-Nukulchai, et al. Eds. Proceedings of the Tenth East Asia-Pacific Conference on Structural Engineering and Construction 05, pages pp. 73-78, Bangkok, Thailand.

USEPA (2009). Estimating 2003 Building-related Construction and Demolition Materials Amounts. http://www.epa.gov/wastes/conserve/imr/cdm/pubs/cd-meas.pdf, accessed on 21/09/2015. 
Wang, J.Y., Li, Z.D., and Tam, V.W.Y. (2014a). Identifying best design strategies for construction waste minimization. Journal of Cleaner Production, 92(4), 237-247.

Wang, W. C., Weng, S. W., Wang, S. H., and Chen, C. Y. (2014b). Integrating building information models with construction process simulations for project scheduling support. Automation in Construction, 37, 68-80.

Wang, Y., Wang, X., Wang, J., Yung, P., and Jun, G. (2013). Engagement of facilities management in design stage through BIM: framework and a case study. Advances in Civil Engineering, 2013, 1-8.

WRAP (2007). Reducing material wastage in construction Available at: http://www2.wrap. org.uk/downloads/Reducing_Material_Wastage_in_Construction.6bf7495b.4711.pdf (accessed 22 September 2015).

Xie, H., Shi, W., and Issa, R. R. (2011). Using rfid and real-time virtual reality simulation for optimization in steel construction. Journal of Information Technology in Construction, 16, 291-308.

Yuan, H., Lu, W., and Hao, J. J. (2013). The evolution of construction waste sorting on-site. Renewable and Sustainable Energy Reviews, 20, 483-490.

Yuan, H.P. (2013). Critical management measures contributing to construction waste management: Evidence from construction projects in China. Project Management Journal, 44(4), 101-112. 


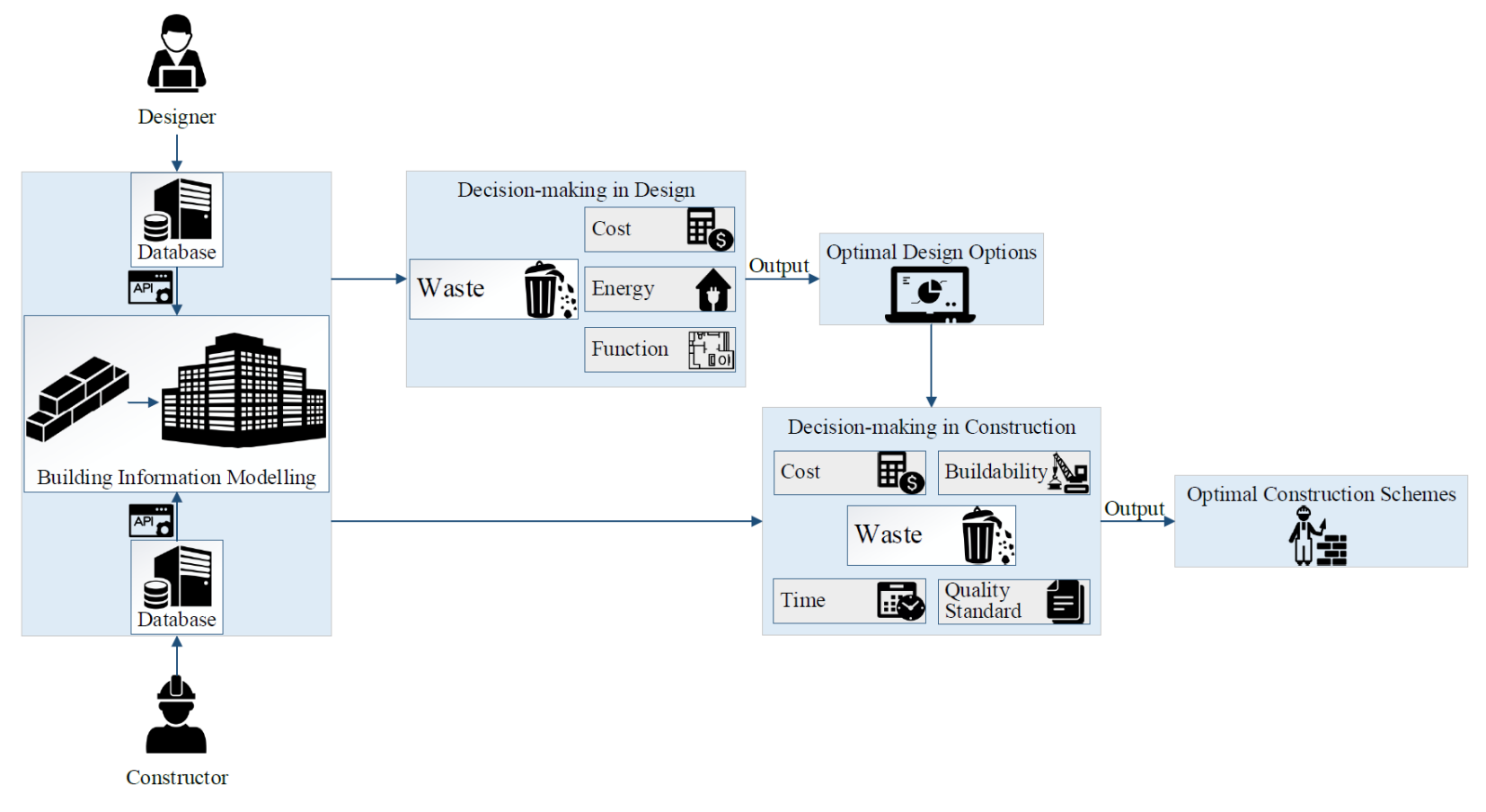

Fig. 1 The prototypical model of computational BIM for construction waste management

象

Designer (1)

列

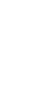




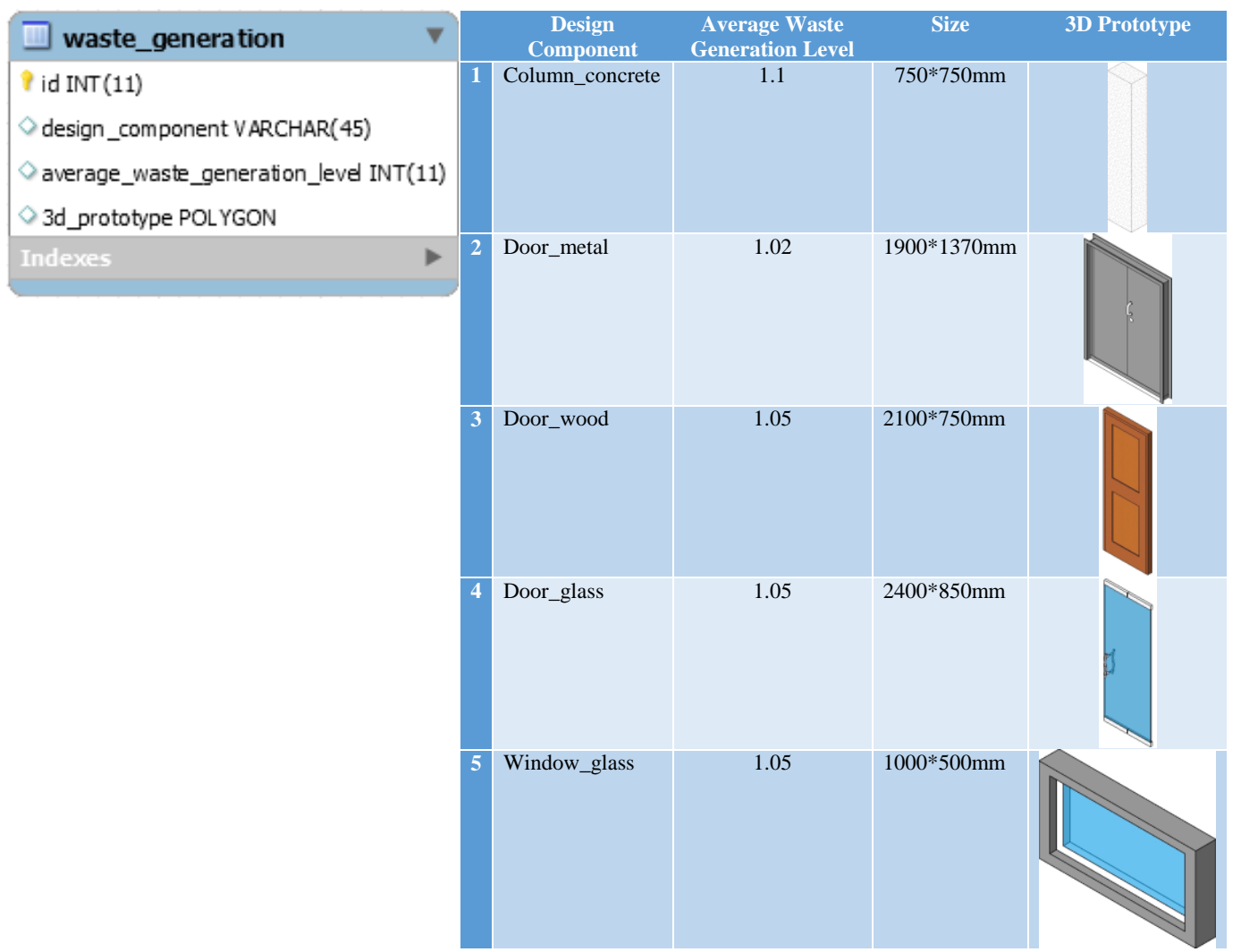

Fig. 2 An illustration of the structure of the design options/construction schemes - waste generation databases 


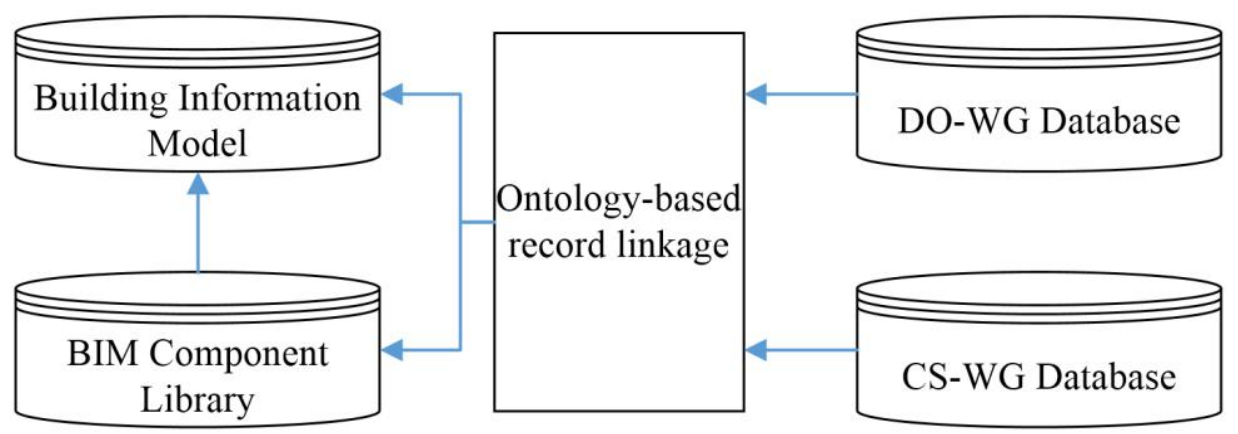

Fig. 3 The standalone design options/construction schemes - waste generation databases and their linkages to BIM component library 


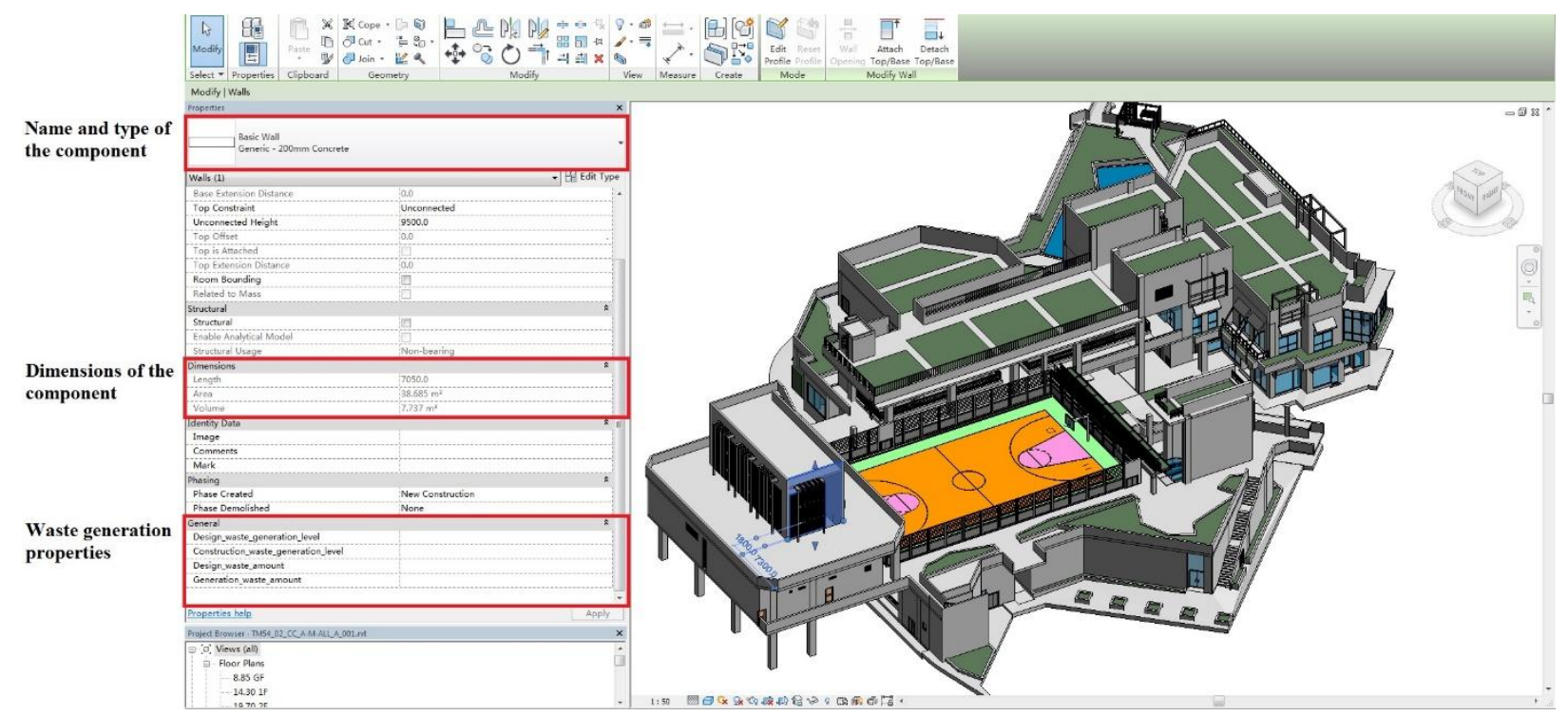

Fig. 4 A screen shot of computational BIM for construction waste management at the design stage 


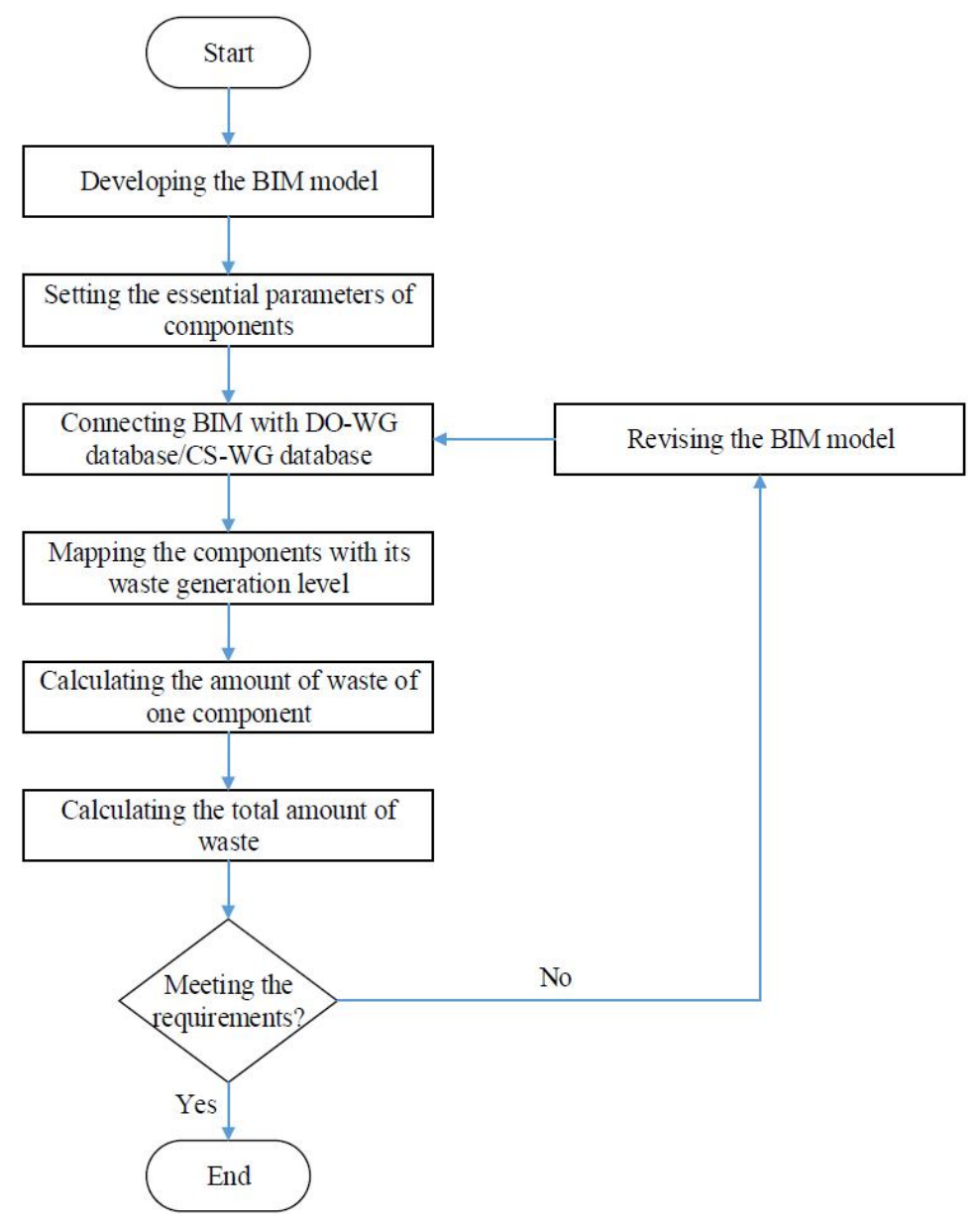

Fig. 5 Flowchart of developing computational BIM for construction waste minimization 
namespace wastegeneration

[TransactionAttribute(Autodesk.Revit.Attributes.TransactionMode.Manual)] public class RevitCommand : IExternalCommand

public Result Execute(ExternalCommandData commandData, ref string messages, ElementSet elements)

UIApplication app $=$ commandData.Application:

Document doc $=$ app. ActiveUIDocument. Document;

Connecting to the

database

string connStr $=$ "SERVER $=127 \cdot 0 \cdot 0.1$; UID=root; DATABASE=waste; PASSWORD=123";

MySqlConnection conn $=$ new MySqlConnection (connStr);

conn.Open();

FilteredElementCollector collector $=$ new FilteredElementCollector (doc, doc.ActiveView.Id), foreach (Element elem in collector)

string elemName = elem. Name;

Acquiring the waste generation level

string sql = "SELECT design_component, average_waste_generation_level FROM design_options_waste_generation"; MySqlDataAdapter SqlDap $=$ new MySqIDataAdapter (sql, conn)

Dataset thisDataset $=$ new DataSet ()

SqlDap.Fill(thisDataset, "design_options_waste_generation"),

DataTable dataTable $=$ thisDataset. Tables["design_options_waste_generation"];

foreach (Datakow row in dataTable. Rows)

if (elemName == row["design_component"].ToString())

\begin{tabular}{|c|c|}
\hline $\begin{array}{l}\text { Setting the properties } \\
\text { of components }\end{array}$ & $\begin{array}{l}\text { Transaction transaction = new Transaction(doc, "waste generation"); } \\
\text { transaction.Start }() ; \\
\text { Parameter } p=\text { elem.LookupParameter("Design_waste_generation_level"); } \\
\text { p.Set(row["average_waste_generation_level"] } \text {. ToString }()) \text {; }\end{array}$ \\
\hline
\end{tabular}

Fig. 6 Part of the codes for calculating the amount of waste relating to each design option 


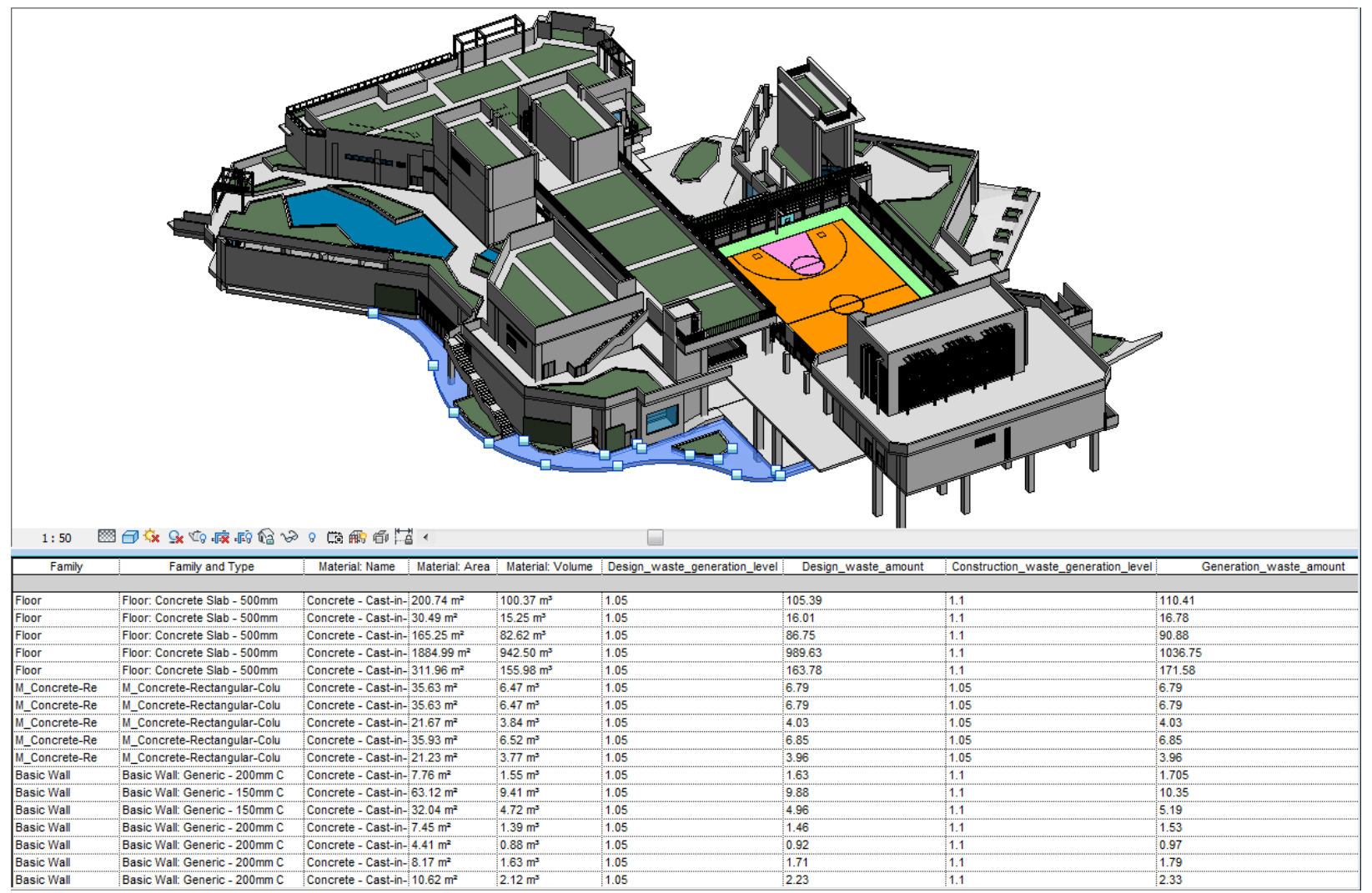

Fig. 7 Screenshot of computational BIM for construction waste management at construction planning stage 